\title{
Fuzzy time series forecasting in determining inventory policy for a small medium enterprise (SME) company
}

\author{
S. Sarifah Radiah Shariff ${ }^{1}$, Nurul Nadiah Abdul Halim ${ }^{2}$, Siti Meriam Zahari ${ }^{3}$, Zuraidah Derasit ${ }^{4}$ \\ ${ }^{1}$ Malaysia Institute of Transport, Universiti Teknologi MARA Shah Alam, Malaysia \\ ${ }^{1,2,3,4}$ Centre for Statistics and Decision Science, Faculty of Computer \& Mathematical Sciences, \\ Universiti Teknologi MARA Shah Alam, Malaysia
}

\section{Article Info \\ Article history: \\ Received Feb 8, 2020 \\ Revised Apr 10, 2020 \\ Accepted Apr 24, 2020 \\ Keywords: \\ Fuzzy forecasting time series Inventory policy \\ Multi-product single line \\ Single production line \\ Small and medium enterprise}

\begin{abstract}
Fuzzy time series models have been widely used to handle forecasting problems, such as forecasting consumer demand and production volume. It is of greater benefits if we have good forecasting accuracy rates especially in managing inventory in a Small and Medium Enterprise (SME) company. This study focuses on multiple products with single production line. The aims of this study are to propose the appropriate the forecasting method for the products, to develop new inventory policy that minimizes the total inventory cost for the company. Simple forecasting methods like trend line, three month moving average (MA (3) and fuzzy time series forecasting are used in this study. The result shows that fuzzy time series forecasting model is suitable to be used in forecasting future demand for all products. The proposed inventory policy is based on the number of cycles per year and the number of productions for each product has helped the company to minimize total inventory cost and schedule the production process accordingly. The proposed inventory policy resulted in lower total inventory cost when compared to current practice.
\end{abstract}

Copyright $\odot 2020$ Institute of Advanced Engineering and Science. All rights reserved.

\section{Corresponding Author:}

S. Sarifah Radiah Shariff,

Malaysia Institute of Transport,

Universiti Teknologi MARA,

Shah Alam, Selangor, Malaysia.

Email: shari990@uitm.edu.my

\section{INTRODUCTION}

Small and medium enterprises (SMEs) in Malaysia can be classified to the manufacturing sector and service sector and other sectors or economic activities which include agricultural, construction, mining and quarrying [1]. In addition to that, according to SME Corp. Malaysia, SMEs can be classified into three groups which are microenterprises, small enterprises, and medium enterprises. The definition of SMEs can be summarized in Table 1.

Table 1. The classification of SMEs in Malaysia

\begin{tabular}{|c|c|c|c|}
\hline Category & Microenterprises & Small enterprise & Medium enterprise \\
\hline Manufacturing & $\begin{array}{l}\text { Sales turnover of less than RM } 300 \text {, } \\
000 \text { OR a number of full-time } \\
\text { employees is less than five. }\end{array}$ & $\begin{array}{l}\text { Sales turnover from RM300, } 000 \text { to } \\
\text { RM15 million OR a number of full-time } \\
\text { employees from five to less than } 75 \text {. }\end{array}$ & $\begin{array}{l}\text { Sales turnover from RM15 } \\
\text { million and not exceed RM50 } \\
\text { million OR a number of full- } \\
\text { time employees from } 75 \text { to } 200 \text {. }\end{array}$ \\
\hline $\begin{array}{l}\text { Services and } \\
\text { other sectors }\end{array}$ & $\begin{array}{l}\text { Sales turnover of less than RM } 300 \text {, } \\
000 \text { OR a number of full-time } \\
\text { employees less than five. }\end{array}$ & $\begin{array}{l}\text { Sales turnover from RM300, } 000 \text { to } \\
\text { RM3 million OR a number of full-time } \\
\text { employees from five to less than } 30 \text {. }\end{array}$ & $\begin{array}{l}\text { Sales turnover from RM3 } \\
\text { million and not exceed RM } 20 \\
\text { million OR a number of full- } \\
\text { time employees from } 30 \text { to } 75 \text {. }\end{array}$ \\
\hline
\end{tabular}


SMEs play an important role in the Malaysian economy as it constitutes $97.3 \%$ of the total registered business establishments where $90 \%$ of business establishments was from the service sectors, 5.9\% from the manufacturing sectors, $3 \%$ from the construction sectors, and agriculture sectors, and mining and quarrying make up $1.0 \%$ and $0.1 \%$ respectively. SMEs increase the employment opportunities in Selangor, Wilayah Persekutuan Kuala Lumpur, Johor, Perak, Sabah and Sarawak [3]. Malaysian SMEs have expanded from a commodity-based on a manufacturing sector producing a variety of consumer goods. Manufacturing sector is a combination of the processing and production of raw materials. For instance, food, beverage, textiles, petroleum, wood rubber and the assembling and manufacturing of electrical of electronics application and components, among others.

For an SME in the manufacturing sector, it is important to remain competitive and maintain profitability in the market by continuously converting raw materials into value-added products that meet the customers' needs. Improper planning and scheduling the production results in higher operating costs [4]. There are two types of scheduling problems which include a deterministic problem and stochastic scheduling problem. Deterministic scheduling deals with constraints and parameters involved in the study already known with certainty. On the other hand, the stochastic scheduling deals with uncertain scheduling problems for example machine breakdown, out of stock of raw materials, unavailability of operators during the production process. This leads to the inefficient production process and unable to meet customers' demand because of the system cannot run the production smoothly. An effective production scheduling helps the management to face with variation in delivery time of raw materials from the supplier, which might occur for some reasons like a shortage of materials at supplier's plant, variation in shipping time and others. Some manufacturers in small medium enterprises (SMEs) produce multi products to fulfill customers' demand and retain to market share. However, different product requires different cycle times, different assembly line or multiple assembly lines to produce one of such. This study focuses on multiple products with single production line and develops a new production schedule that minimizes the inventory costs by proposing an appropriate forecasting method for each product.

There are a few numbers of studies that have been done in inventory management. In a basic inventory management policy, demand is constant over the time and known. However, in real environment demand is dynamic and uncertain as in modelling based on changes over time [5, 6] and the volatility of currency [7]. Thus, many studies have been conducted to determine the appropriate forecasting demand to tame the dynamic and uncertainties of future demand as in stock control [8], foreign exchange [9] and students' enrollment [10]. Among the studies [11-13] proposed fuzzy metric approach for fuzzy time series in order to deal with uncertainties of time series data. The result showed that their proposed method gave a high accuracy of forecasting time series data compared to the existing model which did not consider the uncertainties in data. [14] also conducted a study on forecasting time series data based on fuzzy time series. They used the percentage change as the universe discourse and mean based partitioning in their proposed method. The result showed that their method gave the lowest value of MSE compared to [11]. This study focuses on applying a time series forecasting method using fuzzy techniques in analyzing the inventory policy of multiple products with single production line at a SME. The technique is then use develop a new inventory policy that will minimize the total inventory costs for the company.

\section{RESEARCH METHOD}

In this section, several steps in completing this study are described. The first step is to identify the production sequence, followed by choosing the right forecasting methods in estimating the demand. The acceptability of the forecasting method is analysed based on the minimization of total annual inventory cost. Runout Time (ROT) is a method for sequencing the production for multiple productions using single line. The schedule is based on the depreciation times and the levels of inventory of the item. The first product that needs to be produced is determined by the lowest ROT.

$$
\text { ROT }_{\mathrm{i}}=\frac{\text { Current Inventory Position of Item } \mathrm{i}}{\text { Demand per Period for Item } \mathrm{i}}
$$

Where demand per period in this study refers to the value of forecasting demand by using the proposed method [15].

There are four steps in the fuzzification process in which the universe of discourse $U$ was defined and partitioned into equal lengths interval and considered as the linguistic value. According to [16], the more linguistic values used in the study, it will result a better performance in forecasting. In this study, the partition $\mathrm{U}$ was divided into seven equal lengths of linguistic values since most of the researchers have divided the partition $U$ into seven equal lengths of intervals $[11,17,18]$. The universe of discourse $U=[D m i n-D 1$, Dmax + D2], where Dmin and Dmax represent the minimum and maximum percentage change in demand respectively, whereas the value of D1 and D2 were assumed to be any numbers.

The intervals were then divided to the sub-interval based on the number of data for each interval. According to [11], if there is no data in the interval, then that interval was discarded. Each fuzzy set of Xi was 
defined based on the sub-interval from step 2. The data for actual demand was fuzzified where; Xi represented the linguistic value of the month to month percentage change or known as fuzzy set. The fuzzy data was defuzzified by using the formula (1) on the next page, and the forecast demand was determined by using the percentage change in the monthly demand on the previous month's demand. Based on [12], if the linguistic value is not found in the fuzzy set, the value of first linguistic value is used for the forecast the future demand.

$$
t_{c}= \begin{cases}\frac{1+0.5}{\frac{1}{a_{1}}+\frac{0.5}{a_{2}}} & \text {, if } j=1 \\ \frac{0.5+1+0.5}{0.5} \frac{1}{a_{j-1}}+\frac{0.5}{a_{j}} & , \text { if } 2 \leq j \leq n-2 \\ \frac{0.5+1}{0.5}+\frac{1}{a_{j+1}} & , \text { if } j=n\end{cases}
$$

Where:

$a_{j-1}, a_{j}$ and $a_{j+1}$ represent the midpoints of the fuzzy intervals of $X_{j-1}, X_{j}$, and $X_{j+1}$ respectively. $t_{j}$ represents the predicted percentage change of monthly demand.

The data was divided into two parts. The first part was for model estimation (75\% of the data) and the rest was for evaluation purpose. The evaluation part was used to evaluate the model's forecasting performance. The appropriate model was selected based on the results of comparing the respective error measures mean square error (MSE), mean absolute deviation (MAD) and mean absolute percentage error (MAPE) from the evaluation part. The minimum value of error measured indicates that the model fits well with the actual data and selected as the appropriate model to forecast the future demand for each product. In order to measure the effect of the proposed forecasting method, this study adopted the classical multi-item Economic Production Quantity model based on [19]. This is consistent with may recent studies that consider EOQ in their models to ensure the optimality of the results as when stock dependent under permissible delay [20] and for deteriorating items [21, 22]. The total cost function is given by total production cost, production setup cost and inventory holding cost.

$$
\text { Total cost function, } \operatorname{TCU}\left(m^{*}\right)=\sum_{i=1}^{n} P_{i} R_{i}+2 m^{*} \sum_{i=1}^{n} K_{i}+\sum_{i=1}^{n} H_{i}\left(C_{i}-D_{i}\right)
$$

Where

$$
\begin{aligned}
& m^{*}=\sqrt{\frac{\sum_{i=1}^{n} \frac{H_{i} R_{i}\left(p_{i}-r_{i}\right)}{r_{i}}}{2 \sum_{i=1}^{n} K_{i}}} \\
& Q_{i}=\frac{R_{i}}{m^{*}}
\end{aligned}
$$

Notations:

index $i \in I=\left\{1,2, \ldots, \quad{ }_{1} I\right\}$ is the products

$Q_{i}$ : the optimal production batch size

$K_{i}$ : the fixed cost per production batch

$R_{i}$ : the quarter demand of the product

$H_{i}$ : the holding cost per month

$C_{i}$ : the number of inventory in hand

$D_{i}$ : the number of demand

$m^{*}$ : the optimal number of cycle time

$p_{i}$ : the quarter production rate

$r_{i}$ : the quarter demand rate

$P_{i}$ : unit cost 
For total inventory cost, both holding costs and setup costs are estimated as follows:

The setup cost in this study was estimated by considering the labor cost, setup time of machines and operation time $[23,24]$.

Set up Cost $=C_{s}=\left(R_{o}\right)\left[\frac{T_{s u}}{Q}+t_{o t}\right]$

Where:

$C_{s} \quad$ is the setup cost,

$R_{o} \quad$ is the unit cost rates of labor

$Q \quad$ is the batch quantity

$T_{s u} \quad$ is the setup time of machine

$t_{o t} \quad$ is the operation time required to carry out all the process

Holding cost is associated with the cost to keep or carry inventory in stock which includes storage costs, material handling costs, labor cost and investment costs. In this study, the holding cost was estimated to be of $25 \%$ of the unit cost per unit per year [25].

\subsection{Data setting}

This study conducted in one of food manufacturing company which is located in Terengganu. The company produces 12 types of canned products using a single production line.

In the current setting, the production scheduling is done based on weekly review as follows:

Step 1: Determine minimum requirement for each product.

Step 2: Forecast the demand based on 3 month moving average by marketing department

Step 3: Determine priority of each product based on its demand volume. The higher the volume, the more priority it gets.

Step 4: The products are manufactured periodically. All the finished products will be stored in a warehouse based on three-month inventory policy. This results in congestion in the warehouse.

Since the company has a single production line despite having 12 products, the production runs on a batch system where each product line is produced separately. At the same time, the production capacity of each product is different. In this study, the focus is on six daily demand products which included Sardines in Tomato Sauce 155gm, Sardined in Tomato Sauce 425gm, Family Sardines 405gm, Spicy Anchovies 160gm, Sri Kaya 170gm and Chicken Curry 285gm.

\section{RESULTS AND ANALYSIS}

Table 2 shows the summary and comparison of MSE for all products for three forecasting methods, Moving Average (3 months), Linear Trend line and the proposed fuzzy time series. The fuzzy time series forecasting indicates the lowest MSE values for both estimation and evaluation data sets for 4 items (Sardines in Tomato Sauce 155gm, Sardines in Tomato Sauce 425gm, Family Sardines 405 gm and Chicken Curry $285 \mathrm{gm})$. MSE values are also the lowest when fuzzy time series methods are used for the other two items (Spicy Anchovies 160gm and Sri kaya 170gm), however, it is for only estimation data set for Spicy Anchovies $160 \mathrm{gm}$ and for the evaluation data set for Sri Kaya 170gm.

Table 2. Summary and Comparison of MSE values for 3 forecasting methods

\begin{tabular}{lllll}
\hline \multicolumn{1}{c}{ Item } & \multicolumn{1}{c}{ Part } & MA (3) & \multicolumn{1}{c}{ Linear Trend } & Fuzzy Time Series \\
\hline Sardines in Tomato Sauce 155gm & Estimation & $68,158,541.67$ & $48,708,883.00$ & $6,197,578.80$ \\
& Evaluation & $32,887,278.00$ & $2,761,180.30$ & $953,463.60$ \\
Sardines in Tomato Sauce in 425gm & Estimation & $429,856,080.00$ & $243,773,107.00$ & $5,655,667.11$ \\
& Evaluation & $174,222,976.00$ & $221,876,080.00$ & $4,215,690.84$ \\
Family Sardines 405gm & Estimation & $13,038,464.00$ & $4,261,718.00$ & $18,047.45$ \\
& Evaluation & $5,118,118.00$ & $4,173,836.00$ & $50,062.91$ \\
Spicy Anchovies 160gm & Estimation & $189,142,912.00$ & $77,964,647.00$ & $3,388,239.47$ \\
& Evaluation & $168,666.57$ & $241,462.38$ & $4,537,374.00$ \\
Chicken Curry 285gm & Estimation & $66,445,896.00$ & $30,764,570.00$ & $4,795,876.30$ \\
& Evaluation & $30,370,675.00$ & $58,360,294.00$ & $415,159.49$ \\
Sri Kaya 170gm & Estimation & $71,782.40$ & $57,558.01$ & $52,189.23$ \\
& Evaluation & $1,172,480.00$ & $754,790.80$ & $1,275,764.47$ \\
\hline
\end{tabular}


The appropriate forecast method for each product is determined based on the lowest value of MSE because it shows minimum error between forecasted demand and actual demand (in bold). Fuzzy time series forecasting model is suitable to be used in forecasting future demand for all products produce by the company except for Sri Kaya 170gm which has linear trend forecasting model to be with lowest MSE value.

\subsection{Comparison between current method and proposed method for inventory policy}

Considering the 3-month inventory holding policy, a comparison between the current process and the proposed process are done and analysed based on the number of cycles, number of production time and total inventory cost. Table 3 shows a summary and comparison between the current method and the proposed method on three-month basis. Table 4 shows the comparison on the total annual cost for current practice and the proposed forecasting method, based on the number of for the first quarter, 2013. It clearly shows that the proposed method shows a lower inventory cost with potential saving of RM42, 789.78.

Table 3. Summary and comparison between current method and proposed method

\begin{tabular}{|c|c|c|c|}
\hline Quarter & Elements & $\begin{array}{l}3 \text { Month Demand } \\
\text { (Current Method) }\end{array}$ & $\begin{array}{l}3 \text { Month Demand } \\
\text { (Proposed Method) }\end{array}$ \\
\hline \multirow[t]{10}{*}{1} & Total of 3-month demand & 236,888 & 236,888 \\
\hline & Number of operating days, $N$ & 60 & 60 \\
\hline & Number of cycles, $m^{*}$ & 5 & 8 \\
\hline & The production time for each cycle, $\mathrm{N} / \mathrm{m} *$ & 12 & 8 \\
\hline & Production cost, PiRi (RM) & $747,241.00$ & $745,276.00$ \\
\hline & Setup cost, $C i(\mathrm{RM})$ & $1,359.39$ & $2,157.02$ \\
\hline & Holding cost, $\mathrm{Hi}(\mathrm{RM})$ & $6,892.08$ & $2,787.43$ \\
\hline & Total cost, $T C(\mathrm{RM})$ & $753,524.47$ & $750,235.45$ \\
\hline & Cost saving (RM) & & $3,289.02$ \\
\hline & Percentage of cost saving (\%) & & 0.436 \\
\hline \multirow[t]{10}{*}{2} & Total of 3-month demand & 220,850 & 220,850 \\
\hline & Number of operating days, $N$ & 60 & 60 \\
\hline & Number of cycles, $m^{*}$ & 6 & 7 \\
\hline & The production time for each cycle, $N / m^{*}$ & 10 & 9 \\
\hline & Production cost, PiRi (RM) & $657,363.40$ & $657,363.40$ \\
\hline & Setup cost, $C i(\mathrm{RM})$ & $1,631.26$ & $1,903.14$ \\
\hline & Holding cost, $\mathrm{Hi}(\mathrm{RM})$ & $153,785.52$ & $1,814.94$ \\
\hline & Total cost, $T C(\mathrm{RM})$ & $674,780.18$ & $661,081.48$ \\
\hline & Cost saving (RM) & & $13,968.70$ \\
\hline & Percentage of cost saving (\%) & & 2.07 \\
\hline \multirow[t]{10}{*}{3} & Total of 3-month demand & 218,140 & 218,140 \\
\hline & Number of operating days, $N$ & 60 & 60 \\
\hline & Number of cycles, $m^{*}$ & 5 & 6 \\
\hline & The production time for each cycle, $\mathrm{N} / \mathrm{m} *$ & 13 & 10 \\
\hline & Production cost, PiRi (RM) & $615,592.40$ & $615,592.40$ \\
\hline & Setup cost, $C i(\mathrm{RM})$ & $1,274.84$ & $1,631.26$ \\
\hline & Holding cost, $\mathrm{Hi}(\mathrm{RM})$ & $26,542.27$ & $1,129.37$ \\
\hline & Total cost, $T C(\mathrm{RM})$ & $643,409.51$ & $618,353.03$ \\
\hline & Cost saving (RM) & & $25,056.48$ \\
\hline & Percentage of cost saving (\%) & & 3.89 \\
\hline \multirow[t]{10}{*}{4} & Total of 3-month demand & 247,490 & 247,490 \\
\hline & Number of operating days, $N$ & 60 & 60 \\
\hline & Number of cycles, $m^{*}$ & 4 & 8 \\
\hline & The production time for each cycle, $N / m^{*}$ & 14 & 8 \\
\hline & Production cost, PiRi (RM) & $747,241.00$ & $747,241.00$ \\
\hline & Setup cost, $C i(\mathrm{RM})$ & $1,087.51$ & $2,157.02$ \\
\hline & Holding cost, $\mathrm{Hi}(\mathrm{RM})$ & $2,802.94$ & $1,057.41$ \\
\hline & Total cost, $T C(\mathrm{RM})$ & $751,131.45$ & $750,473.43$ \\
\hline & Cost saving (RM) & & 658.02 \\
\hline & Percentage of cost saving (\%) & & 0.087 \\
\hline
\end{tabular}

Table 4. Comparison of annual total cost for current method and proposed method

\begin{tabular}{lrr}
\hline Annual Total Cost & 3 Month Demand (Current Method) & 3 Month Demand (Proposed Method) \\
\hline Production cost, $P i R i(\mathrm{RM})$ & $2,765,472.80$ & $2,765,472.80$ \\
Setup cost, $C i$ (RM) & $5,437.55$ & $6,786.14$ \\
Holding cost, $H i(\mathrm{RM})$ & $52,022.81$ & $7,884.44$ \\
Total cost, $T C$ (RM) & $2,822,933.16$ & $2,780,143.38$ \\
Total cost saving (RM) & & $42,789.78$ \\
\hline
\end{tabular}




\section{CONCLUSION}

The appropriate forecasting method for each product is chosen based on the smallest value of MSE which indicates the minimum error of forecasting. The fuzzy time series forecasting method is shown to be the most appropriate forecasting method for each product except for Sri Kaya 170gm which is should be forecasted using linear trend line model. The result also shows that the proposed new inventory policy is able to reduce the total inventory costs as compared to the current procedure. Hence, it is recommended that for different product, different forecasting method can be applied in order to ensure more optimal output in any manufacturing environment especially in SMEs.

\section{ACKNOWLEDGEMENTS $\backslash$}

The authors would like to acknowledge Kementerian Pendidikan Malaysia and Universiti Teknologi MARA, Malaysia for funding this research and publication through FRGS: 600-IRMI/FRGS 5/3 (072/2019).

\section{REFERENCES}

[1] Musa, H., and Chinniah, M., "Malaysian SMEs development: future and challenges on going green," Procedia Social and Behavioral Sciences, vol. 224, pp. 254-262, 2016.

[2] SME Corp, "SME Annual Report 2018/19," SME Corporation Malaysia, 2018. [Online]. Available: http://www.smecorp.gov.my/index.php/en/?option=com_content\&view=article\&layout=edit\&id=3911

[3] Department of Statistics Malaysia, "National Accounts Small and Medium Enterprises Gross Domestic Product (SMEs GDP)," 2017. [Online]. Available: https://www.dosm.gov.my [Accessed on October 29, 2017].

[4] S.S.R. Shariff and S. I. Said, "Inventory allocation for offline and online stocks for fashion industry," Advances in Transportation and Logistics Research, vol. 1, no. 1, pp. 403-415, 2018.

[5] M. A. Lazim, "Introductory business forecasting: A pratical approach," 3rd ed., Malaysia: UiTM Press, 2012.

[6] Linawati, M. Sudarma and I. P. O. Wisnawa, "Forecasting rupiah exchange rate with learning vector quantization neural network," Indonesian Journal of Electrical Engineering and Computer Science (IJEECS), vol 18, no. 1, pp. 24-31, 2020.

[7] E. A. Abdullah, S. M. Zahari, S. S. R. Shariff, and M. A. A. Rahim, "Modelling volatility of Kuala Lumpur Composite Index (KLCI) using SV and GARCH models," Indonesian Journal of Electrical Engineering and Computer Science (IJEECS), vol. 13, no. 3, pp.1087-1094, 2019.

[8] A.A. Syntetos, M.Z. Babai, J. Davies and D. Stephenson, "Forecasting and stock control: A study in a wholesaling context," Int. J. Production Economics, vol. 127, no. 1, pp. 103-111, 2010.

[9] R. Rassetiadi and Suharjito, "Foreign exchange prediction based on indices and commodities price using convolutional neural network," Indonesian Journal of Electrical Engineering and Computer Science (IJEECS), vol. 18, no. 1, pp. 494-501, 2020.

[10] P. Saxena, K. Sharma and S. Easo, "Forecasting enrollments based on fuzzy time series with higher forecast accuracy rate," Int. J. Computer Technology \& Applications, vol. 3, no. 3, pp. 957-961, 2012.

[11] T.A. Jilani, S.M.A Burney and C. Ardil, C., "Fuzzy metric approach for fuzzy time series forecasting based on frequency density based partitioning," International Journal of Computer, Electrical, Automation, Control and Information Engineering, vol. 4, no. 7, pp. 1194-1199, 2010.

[12] F. Ye, L. Zhang, D. Zhang, H. Fujita and Z. Gong., "A novel forecasting method based on multi-order fuzzy time series and technical analysis," Information Sciences, vol, 367, no. C, pp. 41-57, 2016.

[13] H. M. Rahman, N. Arbaiy, R. Efendi, C. C. Wen, "Forecasting ASEAN countries exchange rates using auto regression model based on triangular fuzzy number," Indonesian Journal of Electrical Engineering and Computer Science (IJEECS), vol. 14, no. 3, pp. 1525-1532, 2019.

[14] A. Saxena, J. Celaya, B. Saha, S. Saha and K. Goebel, "Metrics for offline evaluation of prognostic performance," International Journal of Prognostics and health management, vol. 1, no. 1, pp. 4-23, 2010.

[15] M. Zare, and M. Koch, "Groundwater level fluctuations simulation and prediction by ANFIS-and hybrid WaveletANFIS/Fuzzy C-Means (FCM) clustering models: Application to the Miandarband plain," Journal of Hydroenvironment Research, vol. 18, pp. 63-76, 2018.

[16] S. M. Chen, "Forecasting enrollments based on high-order fuzzy time series," Cybernetics and Systems: An International Journal, vol. 33, no. 1, pp. 1-16, 2002.

[17] P. Doganis, A. Alexandridis, P. Patrinos and H. Sarimveis, "Time series sales forecasting for short shelf-life food products based on artificial neural networks and evolutionary computing," Journal of Food Engineering, vol. 75, no. 2, pp. 196-204, 2006.

[18] Y.C. Lee, C.H. Wu and S.B. Tsai, "Grey system theory and fuzzy time series forecasting for the growth of green electronic materials," International Journal of Production Research, vol. 52, no. 10, pp. 2931-2945, 2014.

[19] K. Bjork, "A multi-item fuzzy economic production quantity problem with a finite production rate," Int. J. Production Economics, vol. 135, no. 2, pp. 702-707, 2012.

[20] T. Singh, H. Pattanayak, A.K. Nayak, and N.N. Sethy. "An EOQ inventory model with stock dependent demand under permissible delay in payment". International Journal of Logistics Systems and Management, vol. 28, no. 1, pp. 24-41, 2017. 
[21] A.K. Das and T. K. Roy, "An imprecise EOQ model for non-instantaneous deteriorating item with imprecise inventory parameters using interval number". International Journal of Applied and Computational Mathematics, vol. 4, no. 2, pp. 79, 2018.

[22] R.P. Tripathi, "EOQ model for deteriorating items with stock-dependent demand under inflation and trade credits". International Journal of Productivity and Quality Management, vol. 21, no. 2, pp. 229-244, 2018.

[23] K.H. Chang. "Product manufacturing and cost estimating using CAD/CAE: The computer aided engineering design series," United States: Elsevier Inc, 2013.

[24] H.K. Alfares and A.M. Ghaithan, "EOQ and EPQ Production-Inventory Models with Variable Holding Cost: Stateof-the-Art Review". Arabian Journal for Science and Engineering, vol. 44, no. 3, pp. 1737-1755, 2019.

[25] A. Azzi, D. Battini, M. Faccio, A. Persona and F. Sgarbossa, "Inventory holding costs measurement: A multi-case study," The International Journal of Logistics Management, vol. 25, no. 1, pp. 109-132, 2014.

\section{BIOGRAPHIES OF AUTHORS}

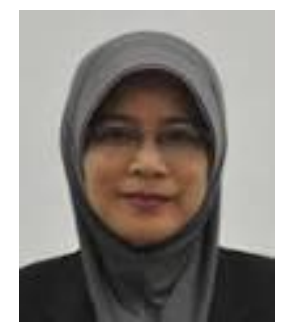

Ts Dr S.Sarifah Radiah Shariff. She is a Senior Lecturer in Centre of Statistics and Decision Science Studies in Faculty of Computer and Mathematical Sciences, Universiti Teknologi MARA, Shah Alam. Her expertise is in Supply Chain and Logistics Modelling. Currently she is attached to Malaysia Institut e of Transport, UiTM.

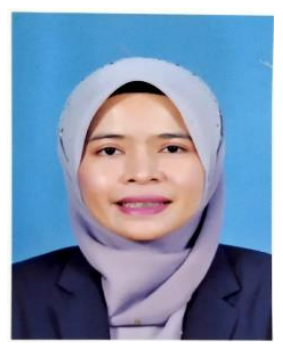

Nurul Nadiah Abdul Halim. She is a doctoral student in Decision Science in Faculty of Computer and Mathematical Sciences, Universiti Teknlogi MARA, Shah Alam, Selangor, Malaysia. She had a Master of Quantitative Sciences specialising in Production analysis.

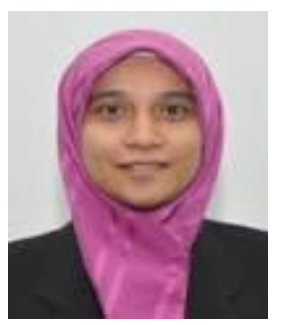

Dr Siti Meriam Zahari. She is a Senior Lecturer in Centre of Statistics and Decision Science Studies in Faculty of Computer and Mathematical Sciences, Universiti Teknologi MARA, Shah Alam. Her expertise is in Econometrics and Time Series.

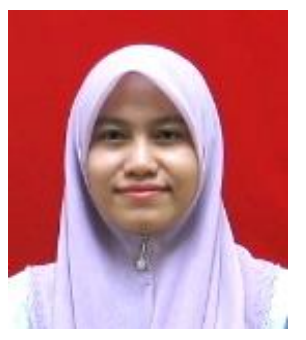

Ms Zuraidah Derasit. She is a Lecturer in Centre of Statistics and Decision Science Studies in Faculty of Computer and Mathematical Sciences, Universiti Teknologi MARA, Shah Alam. Her expertise is in Econometrics and Time Series. 